\title{
Growth, Survival and Fatty Acid Content of Astacus astacus (Linnaeus 1758) In a Water Recirculation System Fed a Semi- Purified Diet
}

\author{
Panagiotis A. Pantazis ${ }^{1 *}$, George Papadomichelakis ${ }^{2}$, John Ch. Karamaligas ${ }^{1}$ \\ ${ }^{1}$ Department of Ichthyology, Aquatic Fauna and Fish Diseases, Faculty of Veterinary Medicine, \\ School of Health Sciences, University of Thessaly, 224 Trikalon Street, Karditsa, Greece. \\ ${ }^{2}$ Laboratory of Animal Nutrition, Department of Animal Sciences and Aquaculture, Agricultural \\ University of Athens, 75 Iera Odos street, Athens, Greece. \\ *ppantazis@vet.uth.gr
}

\begin{abstract}
Continuous environmental disturbances and the crayfish plague have restricted freshwater crayfish populations in Greece. Therefore, the need for the establishment of a repopulation policy in Greece and the increasing commercial interest for the species dictated in the Thessaly County, have imposed the investigation of the optimum husbandry and dietary requirements of Astacus astacus in recirculation systems. Forty-five adult crayfish were placed in nine aquariums in individual chambers for hundred days and fed a semi-purified diet and a diet consisting of fresh fish and carrots. The semi-purified diet had a P: E ratio of $19.71 \mathrm{mg}$ protein/Kj, a protein level of $38.8 \%$ and a lipid level of $13.08 \%$ (on a DM basis). Growth was significantly higher for the crayfish fed the semi-purified diet but more lipids were accumulated in their tail muscle tissue. By the end of the experiment tail muscle levels of EPA \& DHA of both treatments were similar. The high levels of DHA (13-14 mg/100g) and arachidonic acid (ARA 36-41 mg/lo0g) of the tail muscle of all treatments in comparison to the ones of the wild stocks $(6.32 \mathrm{mg} / 100 \mathrm{~g}$ and $13.23 \mathrm{mg} / 100 \mathrm{~g}$ respectively) suggest that the semipurified diet has possibly been over-formulated in terms of corn oil and fish oil.
\end{abstract}

Keywords: purified diets; poly-unsaturated fatty acids; Aphanomyces astaci; freshwater crayfish; RIS 3 strategies.

\section{INTRODUCTION}

There are more than five hundred freshwater crayfish species worldwide [1] while in the European Continent appear five indigenous species and nine imported non-indigenous ones [2]. The industrial revolution in the middle of the $19^{\text {th }}$ and the beginning of the $20^{\text {th }}$ century has created the acidification of natural water reservoirs with negative effect on the survival of existing wild noble crayfish Astacus astacus (Linnaeus 1758) populations. As a result, the remaining "healthy" populations have been over fished, while crayfish plague (Aphanomyces astaci) has further deteriorated the remaining stocks of the species [3, 4]. In Greece, crayfish plague has started to spread in the beginning of the 80's in the noble crayfish populations of the Kalamas River (North-western Greece, Epirus County) and decimated most of existing healthy populations in the adjacent Louros River and the nearby lake of the city of Ioannina [5]. However, some "Greek" noble crayfish populations still exist, have been restricted in water reservoirs of central and north-western Greece and the majority of these populations are plague carriers [6].

The Laboratory of Ichthyology, Aquatic Fauna \& Fish Diseases of the Faculty of Veterinary Medicine of the University of Thessaly is situated by the Karditsa city in the Thessaly County, Greece. Lake Plastira, located to the west of the city of Karditsa (39 $14^{\prime} 39.19^{\prime \prime}$ N, $21^{\circ} 44^{\prime} 20.49^{\prime \prime}$ E) covers an area of $24.4 \mathrm{~km}^{2}$, has a maximum depth of $60 \mathrm{~m}$ and a capacity of $400.000 .000 \mathrm{~m}^{3}$ [7]. The Plastira Lake receives water from the Tavropos River and a number of smaller adjacent streams and torrents (Karitsiotis, Megalo Potami, etc) while the aquifer of its catchment basin is connected to a number of streams and reservoirs all over the Karditsa Prefecture. Locals in the Karditsa Prefecture, report that many of those water reservoirs used to retain noble crayfish populations and that some of those populations still exist. However the latter has not been yet confirmed by official authorities (pers. 
observations and communication with local fishermen and local authorities). Furthermore, recent economic crisis in Greece is impelling many land farmers in the Karditsa Prefecture to replace their traditional crops (i.e. cotton, corn, wheat) with aquaculture activities, using however the same agricultural land and with no exorbitant investment additional costs [8]. Thessaly (Thessalia) is an eligible area under the Convergence Objective and has developed a strategy based on the guidelines of Regional Research and Innovation Strategies (RIS ${ }_{3}$ strategies) for Smart Specialization [9]. In the RIS $_{3}$-Thessaly strategy, it is acknowledged that the primary sector in Thessaly is an activity of strong regional Smart Specialization and is the main driving force for the secondary and tertiary sectors in this region [9].

To this end, it has been decided to investigate the optimum culture conditions of freshwater crayfish, in order to successfully maintain and breed this species in captivity as this species is considered a keystone species for the regional aquaculture-oriented developmental policy. This experiment is the first of a series of experiments aiming at establishing the least-cost artificial diet suitable for freshwater crayfish culture in Thessaly and the effect of such a diet in the crayfish carcass composition and quality. To achieve this, a semi-purified diet has initially been tested in order to clarify the nutritional requirements of this species held in captivity in a water recirculation system and to record the diet's effect on its survival and growth.

\section{MATERIALS AND MeTHODS}

\subsection{Experimental Set Up and Husbandry}

The experimental population originated from wild stocks of northwestern Greece, Epirus County. Forty five freshwater crayfish A. astacus of an Average Weight (A.W.) $=40.8 \mathrm{~g} \pm 4.7$ (SD) and an Average Total Length (A.T.L) $=10.05 \mathrm{~cm} \pm 0.98$ (SD) were placed in nine aquariums situated at the Laboratory of Ichthyology, Aquatic Fauna and Fish Diseases, Faculty of Veterinary Medicine of the University of Thessaly in the city of Karditsa. Each aquarium had a capacity of $285 \mathrm{~L}$ and individual biological filters to keep the recirculating water in a proper physicochemical condition. Each aquarium hosted five crayfish, each crayfish isolated from the rest within an individual chamber (20 $\mathrm{cm}$ X30 $\mathrm{cm}$ X50 cm) made by a stainless steel mesh to avoid intra-specific competition and cannibalism. Individual chambers were place side-by-side to avoid crayfish excreta to pass from one chamber to the other. Crayfish in the six aquariums were fed a purposely prepared semi-purified diet, while crayfish in the rest three of the nine aquariums were fed a "fresh diet" consisting of fresh fish (Engraulis encrasicolus) and fresh carrots [10]. The moisture level (26\%) of the semi-purified diet and the incorporated stability factors (starch, dextrin, CMC) allowed for the diet to keep its dough-like texture, to be able to stick on the mesh of each individual chamber and stay in the water for at least $24 \mathrm{~h}$ without experiencing any severe disintegration. Each crayfish of each respective treatment was fed approximately 6-8g of the semi-purified diet and 7-9g of the "fresh diet", weekly. As soon as the semi-purified diet was stuck on the mesh of each chamber, crayfish were attracted to and sat on it, consuming gradually the chunk of the diet. The "fresh diet" was administered in its fresh form (fish and carrots) and in an alternate way (one day fish, the next day carrots).

\subsection{Experimental Diet and Analytical Methods}

The semi-purified diet was made using fishmeal at $15 \%$, casein at $20 \%$, gelatin at $7 \%$, dextrin at $9 \%$, yeast at 5\%, starch at 14\%, $\alpha$-cellulose at 5\%, CMC ( carboxy methyl cellulose) at $1.5 \%$, cholesterol at $1 \%$, vitamin \& mineral premix, corn oil at $3 \%$, soy oil at $3 \%$ and fish oil at $5 \%$. The diet was prepared manually at the Laboratory of Ichthyology, Aquatic Fauna \& Fish Diseases with the aid of a mixer (Kenwood Cooking Chef, Kenwood, Hampshire, UK) and oven-dried at $40^{\circ}-45^{\circ} \mathrm{C}$ in order to achieve moisture level of $26 \%$. The diet had the following nutritional profile (on a DM basis): Gross Energy $19.65 \mathrm{kj} / \mathrm{gr}$, protein $38.8 \%$, total lipids $13.08 \%$, crude fiber $10.16 \%$, NFE $34.5 \%$, ash $3.45 \%$ and a Protein: Energy $(\mathrm{P}: \mathrm{E})$ ratio $=19.71 \mathrm{mg}$ protein $/ \mathrm{kj}(81.72 \mathrm{mg}$ protein $/ \mathrm{kcal})$. The nutritional profile of the diet has been determined by methods as described in EC regulation No 152/2009 (Official Journal of the European Union, L54/1, 26. 02. 2009).

At the onset of the experiment and before the administration of experimental diets, nine crayfish of the animals captured in the wild (one from each aquarium) have been euthanized and their tail muscle has been subjected to fatty acid analysis [11]. By the end of the experiment, nine individuals fed the semi-purified diet and twelve individuals fed the "fresh diet" were euthanized and their tail muscle 
has been subjected to the Folch-Lees extraction [12] in order to determine their total lipid content and fatty acid composition. For comparison purposes, the same procedure was followed for the semipurified diet itself.

\subsection{Fatty Acid Methyl Ester (FAME) Synthesis and Determination}

The fatty acids of the diets and the entire tail muscle fat were extracted and methylated directly, according to O'Fallon et al. (2007). Duplicate $1 \mathrm{~g}$ samples were hydrolyzed for $1.5 \mathrm{~h}$ at $55{ }^{\circ} \mathrm{C}$ in $1 \mathrm{~N}$ potassium hydroxide in methanol, containing a known amount (approx. $0.5 \mathrm{mg}$ ) of tridecanoic acid (C13:0) methyl ester as an internal standard. The free fatty acids were methylated by sulphuric acid catalysis for $1.5 \mathrm{~h}$ at $55{ }^{\circ} \mathrm{C}$. The fatty acid methyl esters were pipetted into a clean reaction tube and evaporated under a nitrogen stream at $55{ }^{\circ} \mathrm{C}$. Methylesters were then rediluted in $0.5 \mathrm{ml}$ hexane, transferred into gas chromatography vials and kept at $-20{ }^{\circ} \mathrm{C}$. They were subsequently analyzed by gas chromatography in a temperature-programmed run using a Perkin Elmer Autosystem XL gas chromatograph equipped with a $30 \mathrm{~m} \times 0.25 \mathrm{~mm}$ i.d. $\times 0.25 \mu \mathrm{m}$ film thickness HP-Innowax capillary column (Agilent Technologies, J\&W GC columns) and a flame ionisation detector (FID). The oven temperature was programmed for $1 \mathrm{~min}$ at $140^{\circ} \mathrm{C}$, raised by $2.5^{\circ} \mathrm{C} / \mathrm{min}$ to $200^{\circ} \mathrm{C}$, then to $230^{\circ} \mathrm{C}$ by $1^{\circ} \mathrm{C} / \mathrm{min}$ and held for $1 \mathrm{~min}$, and finally to $240^{\circ} \mathrm{C}$ by $4^{\circ} \mathrm{C} / \mathrm{min}$ and held for $10 \mathrm{~min}$. Helium was the carrier gas at a constant pressure of $18 \mathrm{psi}$ and the temperature of both the injector and FID was set at $250^{\circ} \mathrm{C}$. Fatty acids were identified by comparison with standards purchased from Sigma-Aldrich Co. (FAME 37 Component Mix, Supelco). Quantification was achieved using the internal standard added prior to hydrolysis.

Saturated fatty acids (SFA) were the sum of C12:0, C14:0, C15:0, C16:0, C17:0, C18:0, C19:0 andC20:0. Monounsaturated fatty acids (MUFA) were the sum of C14:1, C15:1, C16:1n-7, C17:1n-7, trans-C18:1, C18:1n-9, C18:1n-7 and C20:1, where trans-18:1 was the total of trans-monoenoic isomers (mainly $t \mathrm{C} 18: 1 n-9$ and $t \mathrm{C} 18: 1 n-7$ ).

\subsection{Water Quality and Other Analytical Methods}

Water quality has been recorded by a Hanna C200 / HI83000 spectrophotometer and a Handy Polaris Oxyguard oxygen meter. Statistical analysis of data was performed by ANOVA and the multiple range tests (Duncan and Scheffe) have indicated the statistical differences by using SPSS MS WINDOWS Release 6.1. Software.

\section{RESULTS AND DISCUSSION}

Water quality parameters in the aquariums, have been recorded as follows $(n=37)$ :

$\mathrm{NH}_{3}-\mathrm{N}=0.027 \pm 0.017 \mathrm{mg} / \mathrm{Lt}, \quad \mathrm{NO}_{3}-\mathrm{N}=3.05 \pm 0.21 \mathrm{mg} / \mathrm{Lt}, \quad \mathrm{NO}_{2}-\mathrm{N}=1.1 \pm 0.31 \mathrm{mg} / \mathrm{Lt}, \quad \mathrm{CaCO}_{3}=$ $0.89 \pm 0.037 \mathrm{mg} / \mathrm{Lt}, \mathrm{O}_{2}=80 \pm 10 \%$ saturation, $\mathrm{T}=20^{\circ} \mathrm{C} \pm 0.5$.

Average Weights for both treatments have been recorded as indicated in Table 1.

Table 1. Wet weights ( $g$ ) of freshwater crayfish throughout the experiment

\begin{tabular}{|l|l|l|l|}
\hline & Day-0 & Day-45 & Day-100 \\
\hline Fresh Diet (n=15) & $40.55^{\mathrm{a}} \pm 5.01^{*}$ & $41.45^{\mathrm{a}} \pm 6.42^{* *}$ & $42.01^{\mathrm{a}} \pm 5.04$ \\
\hline Semi-Purified Diet $(\mathrm{n}=25)$ & $41.05^{\mathrm{a}} \pm 5.56$ & $42.52^{\mathrm{b}} \pm 11.94$ & $44.46^{\mathrm{b}} \pm 15.97$ \\
\hline
\end{tabular}

- Similar Superscripts in the same row indicate no differences among the sampling days $(\mathrm{P}>0.05)$.

- ** Represents Standard Deviation

Table 2. Total lipids (\% on a wet basis of muscle tissue) of freshwater crayfish at the termination of the experiment

\begin{tabular}{|l|l|}
\hline & \% of total lipids by Folch-Lees (1957) \\
\hline Crayfish fed the Fresh Diet $(\mathrm{n}=9)$ & $15.09^{\mathrm{a}^{*} \pm 0.79^{* *}}$ \\
\hline Crayfish fed the Semi-Purified Diet $(\mathrm{n}=12)$ & $38.78^{\mathrm{b}} \pm 15.2$ \\
\hline Semi-Purified Diet $(\mathrm{n}=3)$ & $30.98^{\mathrm{c}} \pm 1.1$ \\
\hline
\end{tabular}

- Similar Superscripts in the same column indicate no differences among the sampling days ( $\mathrm{P}>0.05)$.

- ** Represents Standard Deviation 
Crayfish fed the semi-purified diet gained $3 \mathrm{~g}$ of wet weight (on a average) within the 100-day period in comparison with the ones fed the "fresh diet", which did not gain any weight but kept their weight almost stable, till the end of the experiment. The Folch-Lees total lipid determination of the tail muscle of both treatments indicated (Table 2) that crayfish fed the semi-purified diet accumulated more lipids in their tail muscle tissue; however this difference did not affect their survival among treatments. Fatty acid profiles of the semi-purified diet and the tail muscle of experimental animals are shown in Tables 3 and 4.

Table 3. Fatty acid profile of the Semi-Purified Diet (SPD) \& the Tail Muscle of A. astacus at the Onset of the experiment (TMON).

\begin{tabular}{|c|c|c|c|c|}
\hline & $\begin{array}{l}\mathrm{mg} / 100 \mathrm{~g} \text { Wet } \\
\text { Weight(SPD) }\end{array}$ & $\begin{array}{l}\text { As \% total FAMEs } \\
\text { (SPD) }\end{array}$ & $\begin{array}{c}\mathrm{mg} / 100 \mathrm{~g} \mathrm{Wet} \\
\text { Weight (TMON) }\end{array}$ & $\begin{array}{c}\text { As \% of total } \\
\text { FAMEs (TMON) }\end{array}$ \\
\hline $12: 0$ & $6.27 \pm 0.16^{*}$ & $0.091 \pm 0.00023$ & $3.75 \pm 0.14 * *$ & $1.21 \pm 0.012$ \\
\hline 14:0 & $195.6 \pm 0.57$ & $2.83 \pm 0.064$ & $1.95 \pm 0.47$ & $0.63 \pm 0.023$ \\
\hline -14:1 & $2.44 \pm 0.43$ & $0.035 \pm 0.007$ & $0.3 \pm 0.17$ & $0.096 \pm 0.041$ \\
\hline C15:0 & $14.65 \pm 0.37$ & $0.21 \pm 0$ & $0.9 \pm 0.45$ & $0.29 \pm 0.06$ \\
\hline $16: 0$ & $957.4 \pm 14.62$ & $13.84 \pm 0.15$ & $38.66 \pm 4.32$ & $12.41 \pm 1.13$ \\
\hline $7 \mathrm{c} 16: 1$ & $8.71 \pm 0.27$ & $0.125 \pm 0.007$ & $0.5 \pm 0.01$ & $0.16 \pm 0.035$ \\
\hline $9 c 16: 1$ & $151.3 \pm 0.071$ & $2.19 \pm 0.056$ & $2.2 \pm 0.16$ & $0.71 \pm 0.23$ \\
\hline $17: 0$ & $10.48 \pm 1.25$ & $0.15 \pm 0.014$ & $0.9 \pm 0.23$ & $0.29 \pm 0.08$ \\
\hline 17:1 & $10.12 \pm 0.75$ & $0.145 \pm 0.007$ & $0.8 \pm 0.36$ & $0.26 \pm 0.021$ \\
\hline 18:0 & $250.4 \pm 6.39$ & $3.62 \pm 0$ & $26.52 \pm 9.32$ & $8.52 \pm 1.22$ \\
\hline 9c18:1 & $1753 \pm 62.056$ & $25.32 \pm 0.25$ & $79.8 \pm 12.7$ & $25.62 \pm 2.08$ \\
\hline 11c18:1 & $102.2 \pm 2.11$ & $1.475 \pm 0.007$ & $3.6 \pm 0.24$ & $1.16 \pm 0.67$ \\
\hline $18: 2 n-6$ & $1909 \pm 37.97$ & $27.59 \pm 0.16$ & $13.09 \pm 2.9$ & $4.203 \pm 1.32$ \\
\hline $18: 3 n-3$ & $122.7 \pm 2.16$ & $1.77 \pm 0.014$ & $0.42 \pm 0.14$ & $0.14 \pm 0.09$ \\
\hline c20:0 & $29.99 \pm 0.77$ & $0.432 \pm 0.0023$ & $1.97 \pm 0.07$ & $0.63 \pm 0.05$ \\
\hline 20:1n-9 & $231.2 \pm 6.40$ & $3.34 \pm 3.53 * 10^{-05}$ & $10.92 \pm 1.1$ & $3.51 \pm 0.24$ \\
\hline $20: 2$ & $8.73 \pm 0.71$ & $0.125 \pm 0.007$ & $1.25 \pm 0.43$ & $0.401 \pm 0.08$ \\
\hline $20: 4 n-6$ & $8.37 \pm 0.21$ & $0.121 \pm 0.00064$ & $13.23 \pm 4.7$ & $4.25 \pm 2.05$ \\
\hline $20: 3 n-3$ & $5.58 \pm 0.14$ & $0.0803 \pm 0.00043$ & $3.3 \pm 0.9$ & $1.06 \pm 0.91$ \\
\hline $20: 5 n-3$ & $98.68 \pm 2.029$ & $1.43 \pm 0.007$ & $93.16 \pm 7.1$ & $29.91 \pm 4.32$ \\
\hline $22: 1 n-9$ & $39.74 \pm 0.028$ & $0.57 \pm 0.014$ & 0 & 0 \\
\hline $22: 2$ & $44.62 \pm 0.15$ & $0.64 \pm 0.014$ & $1.3 \pm 0.69$ & $0.42 \pm 0.01$ \\
\hline $22: 4 n-6$ & $2.09 \pm 0.056$ & $0.031 \pm 0.00016$ & $1.2 \pm 0.73$ & $0.39 \pm 0.07$ \\
\hline $22: 5 n-3$ & $19.53 \pm 0.50$ & $0.281 \pm 0.0015$ & $0.43 \pm 0.13$ & $0.14 \pm 0.04$ \\
\hline $22: 6 n-3$ & $145.1 \pm 5.68$ & $2.1 \pm 0.028$ & $6.32 \pm 3.22$ & $2.03 \pm 0.96$ \\
\hline SUMWFA & $6922 \pm 177.94$ & $88.51 \pm 0.19$ & $311.47 \pm 91.7$ & 100 \\
\hline $\begin{array}{c}\text { Total } \\
\text { Saturates }\end{array}$ & $1465 \pm 24.13$ & $21.16 \pm 0.19$ & $79.65 \pm 21.3$ & $25.57 \pm 0.18$ \\
\hline $\begin{array}{c}\text { Total } \\
\text { Monoenes }\end{array}$ & $2298 \pm 70.58$ & $33.2 \pm 0.16$ & $98.12 \pm 22.6$ & $31.5 \pm 1.96$ \\
\hline Total n-3 & $391.6 \pm 10.52$ & $5.66 \pm 0.009$ & $103.63 \pm 18.7$ & $33.27 \pm 2.63$ \\
\hline Total n-6 & $1920 \pm 38.24$ & $27.74 \pm 0.16$ & $27.52 \pm 11.7$ & $8.84 \pm 2.88$ \\
\hline Total n-9 & $2175 \pm 68.42$ & $31.42 \pm 0.17$ & $92.92 \pm 14.5$ & $29.83 \pm 2.23$ \\
\hline$n-3 / n-6$ & $0.204 \pm 0.0014$ & $0.204 \pm 0.0015$ & $3.76 \pm 0.72$ & $3.76 \pm 0.72$ \\
\hline DHA/EPA & $1.47 \pm 0.027$ & $1.47 \pm 0.027$ & $0.068 \pm 0.2$ & $0.068 \pm 0.2$ \\
\hline
\end{tabular}

* Represents Standard Deviation $(\mathrm{n}=3) * *$ Values in the same row have been tested by ANOVA and found different $(\mathrm{P}<0.05)$.

The prepared artificial diet has managed to sustain the crayfish experimental populations without creating any adverse effects on their survival and growth. Furthermore this semi-purified diet has managed to create a tail muscle fatty acid profile similar to that of the crayfish fed the "fresh diet". By the end of the experiment tail muscle levels of EPA \& DHA of animals of all treatments were similar in terms of $\mathrm{mg} / 100 \mathrm{~g}$ of tail carcass and as \% of total FAMEs. However, EPA levels of the tail carcass of the animals caught in the wild (onset of the experiment) were higher $(93.1 \mathrm{mg} / 100 \mathrm{~g})$ than those observed by the end of the experiment, while DHA levels by the end of the experiment (and for all treatments) were higher and almost twice as much (13-14 mg/100g of those observed at the onset (wild stock) of the experiment $(6.32 \pm 3.22 \mathrm{mg} / 100 \mathrm{~g})$. These findings can be attributed to the low $\mathrm{n}$ $3 / n-6$ ratio $(=0.2)$ of the semi-purified diet and its high content in linoleic acid \& DHA, due to the 
incorporation of unbalanced ratios among the vegetable oils and fish oil. It is then understandable that the semi-purified diet has possibly been over-formulated in terms of $n-6$ fatty acids and its $n-3 / n-6$ ratio (0.2) should be closer to the one of the tail carcass of the animals caught in the wild (n-3/n-6 =3.7). Similarly, other researchers in the past have shown that $n-3$ fatty acids (originating from clupeid fish oil) are essential for A. leptodactylus [12]. The levels of arachidonic acid in the tail carcass of the animals fed the artificial diet were quite high (36 mg/100g) compared to those of the animals caught in the wild $(13.23 \mathrm{mgr} / 100 \mathrm{~g})$ confirming the high levels of linoleic acid in the artificial diet. It has been shown that linoleic acid is an essential one for A. astacus [13] however it might have been overdosed in this experiment.

Table 4. Fatty Acid profile of the Tail Muscle of the crayfish fed the Fresh Diet (TMFD) and the Tail Muscle of the crayfish fed the Semi-Purified Diet (TMSPD)

\begin{tabular}{|c|c|c|c|c|}
\hline & $\begin{array}{c}\mathrm{mg} / 100 \mathrm{~g} \text { Wet } \\
\text { Weight } \\
\text { (TMFD) }\end{array}$ & $\begin{array}{c}\text { As } \% \text { of total FAMEs } \\
\text { (TMFD) }\end{array}$ & $\begin{array}{l}\mathrm{mg} / 100 \mathrm{~g} \text { Wet Weight } \\
\text { (TMSPD) }\end{array}$ & $\begin{array}{c}\text { As } \% \text { of total FAMEs } \\
\text { (TMSPD) }\end{array}$ \\
\hline $12: 0$ & $0.60 \pm 0.12 *$ & $0.16 \pm 0.015$ & $0.43 \pm 0.153^{* *}$ & $0.104 \pm 0.015$ \\
\hline $14: 0$ & $1.68 \pm 0.48$ & $0.45 \pm 0.04$ & $1.82 \pm 0.5$ & $0.45 \pm 0.033$ \\
\hline 14:1 & $0.42 \pm 0.28$ & $0.12 \pm 0.06$ & $0.28 \pm 0.28$ & $0.063 \pm 0.057$ \\
\hline C15:0 & $1.35 \pm 0.59$ & $0.36 \pm 0.11$ & $1.19 \pm 0.58$ & $0.29 \pm 0.101$ \\
\hline $16: 0$ & $40.51 \pm 4.7$ & $10.81 \pm 1.33$ & $47.06 \pm 4.64$ & $11.97 \pm 1.33$ \\
\hline 7c16:1 & $1.77 \pm 0.58$ & $0.48 \pm 0.05$ & $1.55 \pm 0.46$ & $0.38 \pm 0.045$ \\
\hline 9c16:1 & $10.04 \pm 2.68$ & $2.68 \pm 0.33$ & $6.91 \pm 2.77$ & $1.69 \pm 0.328$ \\
\hline $17: 0$ & $3.78 \pm 1.17$ & $1.01 \pm 0.08$ & $3.81 \pm 1.16$ & $0.94 \pm 0.082$ \\
\hline 17:1 & $3.49 \pm 0.64$ & $0.93 \pm 0.03$ & $2.72 \pm 0.64$ & $0.68 \pm 0.031$ \\
\hline 18:0 & $35.38 \pm 10.56$ & $9.45 \pm 1.06$ & $41.01 \pm 13.56$ & $10.11 \pm 1.051$ \\
\hline 9c18:1 & $60.30 \pm 11.96$ & $16.09 \pm 2.09$ & $70.19 \pm 12.96$ & $17.7 \pm 2.094$ \\
\hline 11c18:1 & $11.22 \pm 3.34$ & $2.99 \pm 0.81$ & $12.98 \pm 6.34$ & $3.13 \pm 0.813$ \\
\hline $18: 2 n-6$ & $8.07 \pm 2.13$ & $2.15 \pm 0.86$ & $13.55 \pm 3.13$ & $3.60 \pm 1.422$ \\
\hline $18: 3 n-3$ & $0.55 \pm 0.19$ & $0.15 \pm 0.07$ & $0.78 \pm 0.40$ & $0.21 \pm 0.14$ \\
\hline c20:0 & $1.05 \pm 0.07$ & $0.28 \pm 0.063$ & $0.88 \pm 0.07$ & $0.23 \pm 0.065$ \\
\hline 20:1n-9 & $3.90 \pm 0.87$ & $1.043 \pm 0.30$ & $6.06 \pm 1.0$ & $1.54 \pm 0.302$ \\
\hline $20: 2$ & $4.79 \pm 0.63$ & $1.28 \pm 0.19$ & $6.57 \pm 0.64$ & $1.67 \pm 0.188$ \\
\hline $20: 4 n-6$ & $40.55 \pm 9.17$ & $10.82 \pm 3.86$ & $36.26 \pm 11.17$ & $9.50 \pm 3.859$ \\
\hline $20: 3 n-3$ & $5.25 \pm 1.25$ & $1.41 \pm 3.9$ & $12.02 \pm 19.66$ & $2.45 \pm 3.902$ \\
\hline $20: 5 n-3$ & $61.64 \pm 6.87$ & $16.45 \pm 4.2$ & $53 \pm 6.91$ & $13.89 \pm 4.313$ \\
\hline $22: 1 n-9$ & 0 & 0 & 0 & 0 \\
\hline $22: 2$ & $3.4 \pm 0.72$ & $0.91 \pm 0.04$ & $3.99 \pm 0.73$ & $1.01 \pm 0.039$ \\
\hline $22: 4 n-6$ & $2.65 \pm 0.8$ & $0.71 \pm 0.082$ & $2.35 \pm 0.86$ & $0.58 \pm 0.084$ \\
\hline $22: 5 n-3$ & $0,63 \pm 0.34$ & $0.17 \pm 0.042$ & $0.93 \pm 0.34$ & $0.23 \pm 0.041$ \\
\hline $22: 6 n-3$ & $13.32 \pm 6.47$ & $3.56 \pm 1.77$ & $14.98 \pm 7.75$ & $3.73 \pm 1.76$ \\
\hline $\begin{array}{c}\text { SUMW } \\
\text { FA }\end{array}$ & $328.96 \pm 93.74$ & $87.79 \pm 5.32$ & $390.16 \pm 94.74$ & $88.42 \pm 5.23$ \\
\hline $\begin{array}{c}\text { Total } \\
\text { Saturat } \\
\text { es }\end{array}$ & $84.33 \pm 22.41$ & $22.51 \pm 0.18$ & $105.35 \pm 22.42$ & $26.38 \pm 0.18$ \\
\hline $\begin{array}{c}\text { Total } \\
\text { Monoe } \\
\text { nes }\end{array}$ & $91.14 \pm 22.76$ & $24.32 \pm 1.95$ & $100.68 \pm 22.81$ & $25.19 \pm 1.96$ \\
\hline $\begin{array}{c}\text { Total n- } \\
3 \\
\end{array}$ & $81.39 \pm 18.7$ & $21.72 \pm 2.72$ & $81.71 \pm 19.5$ & $20.5 \pm 2.74$ \\
\hline $\begin{array}{c}\text { Total n- } \\
\quad 6 \\
\end{array}$ & $51.26 \pm 11.32$ & $13.68 \pm 4.78$ & $52.16 \pm 12.32$ & $13.67 \pm 4.88$ \\
\hline $\begin{array}{l}\text { Total n- } \\
\quad 9\end{array}$ & $13.95 \pm 5.7$ & $3.73 \pm 1.09$ & $83.16 \pm 15.7$ & $20.93 \pm 2.09$ \\
\hline n-3/n-6 & $1.59 \pm 0.74$ & $1.59 \pm 0.74$ & $1.68 \pm 0.74$ & $1.68 \pm 0.74$ \\
\hline $\begin{array}{c}\text { DHA/E } \\
\text { PA }\end{array}$ & $0.22 \pm 0.08$ & $0.22 \pm 0.08$ & $0.296 \pm 0.18$ & $0.296 \pm 0.18$ \\
\hline
\end{tabular}

* Represents Standard Deviation $(\mathrm{n}=3)$ ** Values in the same row have been tested by ANOVA and found different $(\mathrm{P}<0.05)$. 
In terms of other nutrients the prepared semi-purified diet in this experiment has been very similar to diets prepared for A. leptodactylus in previous experiments $[14,15]$. Other researchers in the past $[16]$ have investigated the nutrient requirements of $A$. astacus but in very early juveniles $(0.1-0.2 \mathrm{~g})$. For older animals, they suggest protein levels $<35 \%$, lipid levels a bit higher than $10 \%$ and carbohydrate (CHOs) levels at least $20-25 \%$. For older animals they also suggest a P/E ratio $<115 \mathrm{mg} / \mathrm{kcal}$ and a lipid/CHO ratio of at least 0.4 ( 0.38 in the semi-purified diet of this experiment).

It is then understandable that adult noble crayfish require a more refined diet, not just on the level of $\mathrm{n}-3 / \mathrm{n}-6$ fatty acids but also on the level of $\mathrm{P} / \mathrm{E}$ ratio and lipid/CHO ratio.

Survival rates have been recorded as $70 \%-75 \%$ for both treatments. Despite the existence of custommade individual mesh chambers, crayfish in adjacent chambers got into territorial quarrels and occasional loss of some walking legs. It has been observed that the majority of mortalities were attributed to these mutilations due to territorial quarrels. A smaller percentage of mortalities can be attributed to the pathogen A. astaci with well substantiated symptoms: abdomen folded under the cephalothorax, walking legs in a permanent extended position, permanent overturn of the animal with dorsal area sitting on the bottom of the tank, white hyphae of fungi protruding through the exoskeleton particularly in the areas of articular membranes [3, 17].

\section{Conclusions}

The present study has indicated the capacity of the freshwater crayfish A. astacus to survive and grow in water-recirculated systems fed an artificial diet. Further investigation of the fatty acid profile, the $\mathrm{P} / \mathrm{E}$ ratio and the lipid/CHO ratio of the administered diet will not only elucidate the optimum dietary requirements of the species at the adult phase but will also improve its carcass quality when held in water-recirculated systems. In addition, the determination of optimum conditions for its successful reproduction in such systems and its respective appropriate nutritional requirements for the reproductive phase will enable us to maintain and propagate this species in captivity, successfully.

\section{ACKNOWLEDGEMENTS}

This research has been funded by the University of Thessaly Research Committee (Project Code Nos $3747 \& 4510)$.

\section{REFERENCES}

[1] Crandall K.A. and Buhay J.E. (2008). Global diversity of crayfish (Astacidae, Cambaridae, and Parastacidae-Decapoda) in freshwater. Hydrobiologia, 595, 295-301.

[2] Holdich D.M., Reynolds J.D., Souty-Grosset C. and Sibley, P.J. (2009). A review of the ever increasing threat to European crayfish from non-indigenous crayfish species. Knowledge and Management of Aquatic Ecosystems, 11, 394-395.

[3] Arrignon J. (1990) (2 ${ }^{\text {nd }}$ ed.). L'écrevisse et son élevage. Gauthier-Villars. Paris. (Collection "Nature et Agriculture"), France.

[4] Westman K, Pursiainen M. and Westman, P. (1990). Status of crayfish stocks, fisheries, diseases and culture in Europe. Report of the FAO European Inland Fisheries Advisory Commission (EIFAC) working party on crayfish. RKTL, Kalatutkimuksia 3, 1990. Helsinki, Finland.

[5] Theocharis V. 1986. La pêche a l'écrevisse dans la région d' Hipiros en Grèce. Station de recherches de Louros, Ministère Grec de l'Agriculture, Ioannina. Bulletin publie par l'Association des Astaciculteurs de France, Bulletin No 8, France.

[6] Koutrakis E., Perdikaris C., Machino Y., Savvidis G. and Margaris, N. (2007). Distribution, recent mortalities and conservation measures of crayfish in Hellenic freshwaters. Bulletin français de la Pêche et de la Pisciculture, 385: 25-44.

[7] Stefanidis P. (2001). Torrential environment of the catchment area of Lake Tavropos. Project LIFE 99NAT/GR/6480.

[8] Regional Council of Thessaly, Regional Innovation Strategy for Smart Specialisation (RIS3) of Thessaly for the programming period 2014-2020 (2015). http://www.thessaly.gov.gr/main.aspx?catid=178\# [accessed February 4, 2016]

[9] European Commission, European Cohesion Policy in Greece, Cohesion Policy 2007-2013 (2014).http://ec.europa.eu/regional_policy/sources/docgener/informat/country2009/el_en.pdf[Ac cessed February 4 2016] 
[10] Ackefors H., Castell J. and Örde-Öström I.-L. 1997. Preliminary results on the fatty acid composition of freshwater crayfish, Astacus astacus and Pacifastacus leniusculus, held in captivity. Journal of the World Aquaculture Society, 28 (1), 97-105.

[11] O'Fallon J.V, Busboom J.R, Nelson M.L. and Gaskins C.T. (2007). A direct method for fatty acid methyl ester synthesis: Application to wet meat tissues, oils, and feedstuffs. Journal of Animal Science , 85, 1511-1521.

[12] Folch J, Lees M. and Stanley GHS. (1957). A simple method for the isolation and determination of total lipids from animal tissues. Journal of Biological Chemistry 226, 497-509.

[13] Valipour A., Shariatmadari F., Abedian A., Seyfabadi S.J. \& Zahmatkesh, A. (2011). Growth, moulting and survival response of juvenile narrow clawed crayfish, Astacus leptodactylus, fed two sources of dietary oils. Iranian Journal of Fisheries Sciences, 10(3), 505-518.

[14] Zandee D.I. (1966). Metabolism in the crayfish Astacus astacus (L.). IV. The fatty acid composition and the biosynthesis of the fatty acids. Archives Internationales de Physiologie et de Biochimie, 74(4), 614-626.

[15] Harlioglu M.M., Cakmak M.N., Koprucu K., Aksu O., Harlioglu A.G., Yonar S.M., Duran T.C., Ozcan S. and Gundogdu, H. (2013). The effect of dietary n-3 series fatty acids on the number of pleopodal egg and stage 1 juvenile in freshwater crayfish, Astacus leptodactylus Eschscholtz. Aquaculture Research, 44, 860-868.

[16] Safari O., Shahsavani D., Paolucci M., and Masoomeh Mehraban Sang Atash. (2014). Screening of selected feedstuffs by sub-adult narrow clawed crayfish, Astacus leptodactylus leptodactylus Eschscholtz, 1823. Aquaculture, 420-421, 211-218.

[17] Ackefors H., Castell J.D., Boston L.D., Raty P. and Svensson, M. (1992). Standard experimental diets for crustacean nutrition research. II. Growth and survival of juvenile crayfish Astacus astacus (Linne) fed diets containing various amounts of protein, carbohydrate and lipid. Aquaculture, 104, 341-356.

[18] Polglase J. and Alderman D. (1984). Crayfish plague threatens U.K. stock. Fish Farmer, 7(3), 16-17. 